\title{
Stimulus generalization according to palatability in lithium-chloride- induced taste aversions
}

\author{
OLIVER T. MASSEY and WILLIAM H. CALHOUN \\ University of Tennessee, Knoxville, Tennessee 37916
}

\begin{abstract}
Generalization of a conditional taste aversion to novel flavors was examined in the rat. Using a two-bottle choice test, the relative palatability for seven flavors was determined. Two of the moderately palatable flavors, lemon and peppermint-sucrose, were paired with an injection of lithium chloride (5 ml/kg .36 M LiC1 IP). Each of the seven flavors was then reranked in a second test for the lithium-chloride-injected animals. Results indicate that palatable flavors generalize to taste aversions less readily than do those flavors which are less palatable.
\end{abstract}

Early experimenters (e.g., Richter, 1953; Rzoska, 1953) noted the generalization of taste aversions to other flavors. Since that time, however, researchers have, for the most part concentrated on discovering the characteristics of the conditioned stimulus (CS) conducive to the formation of taste aversions. From these studies, novelty, salience, and palatability have been established as three important variables. The strength of the conditioned aversion is directly related to the novelty of the CS (Vogel \& Clody, 1972) and the salience of the CS (Kalat \& Rozin, 1970). Palatability (i.e., initial preference) has been similarly examined, but with less clear-cut results (Brackbill, Rosenbush, \& Brookshire, 1971; Etscorn, 1973).

In recent experiments, novelty also has been shown to be a factor governing stimulus generalization of conditioned taste aversions (Domjan, 1975), but little is known of other factors influencing generalization. The present experiment is an attempt to determine what role the factor of palatability serves in the generalization of aversions. Since novelty is a potent factor in determining behavior, it is hypothesized that a conditioned taste aversion to a novel flavor will generalize to other novel flavors. It is also true that palatability is a potent factor affecting behavior, and it is further hypothesized that a conditioned aversion will generalize more to less palatable flavors than to more palatable flavors.

\section{METHOD}

\section{Subjects and Apparatus}

Two groups of eight Sprague-Dawley rats approximately 105 days old served as subjects. All animals were individually caged in standard plastic cages with wire lids, and all testing was done in the home cages. Water and test solutions were provided on each side of the feeding trough by inverted $100-\mathrm{ml}$ graduated cylinders with stainless steel drinking tubes. Purina Lab Chow was available ad lib throughout the experiment in the area of the trough between the drinking tubes. Flavors consisted of Kroger-brand extracts in tap-water solution in the following percentages: chocolate, $.2 \%$; peppermint, $.2 \%$; vanilla, $.4 \%$; lemon, $.4 \%$. The three sucrose flavors consisted of a $2 \%$ sucrose solution alone and combined with chocolate and peppermint in $.2 \%$ concentrations.

\section{Procedure}

The two phases of the experiment were run consecutively and eight rats were used in each phase. Different rats were used in the two phases to insure that familiarity with the CS was not a factor in the testing phase of the experiment. The first phase consisted of ranking the seven flavors according to palatability as discerned from relative preference to tap water. All animals were allowed to habituate to the home cages until water consumption had reached approximately $50 \%$ for each side. Beginning on Day 1, each animal was presented one of the seven test flavors and tap water in a two-bottle preference test. On Day 2 each animal received its Day 1 flavor on the opposite side of the cage; on Day 3 all animals received tap water on both sides. This sequence was repeated until all animals had received all flavors. Flavors were presented in a counterbalanced order. After all the flavors had been presented, they were ranked according to preference to tap water, and two moderately palatable flavors, lemon and peppermint-sucrose, were picked as test flavors to be paired with lithium chloride in the tasteaversion procedure.

The second phase of the experiment consisted of pairing the test flavors with lithium chloride for a second group of rats and, subsequently, exposing these animals to the seven flavors ranked in Phase 1. Each flavor was then reranked for palatability (i.e., compared with palatability ratings from the first group). The eight rats in the second phase of the experiment were allowed to habituate to cages, as were the Phase 1 animals. After habituation, all animals were water deprived for $23 \mathrm{~h}$ prior to Day 1 of the testing phase. At the end of the 23-h deprivation period on Day 1 , animals were allowed access to a $.4 \%$ lemon solution on both sides of the cage for $30 \mathrm{~min}$. At the end of the 30 -min period, the animals were injected with lithium chloride solution and returned to their cages $(5 \mathrm{ml} / \mathrm{kg} .36 \mathrm{M} \mathrm{LiCl} \mathrm{IP)}$. All animals received water on both sides of the cage for the following 2 days. On Day 3 animals were again water deprived for $23 \mathrm{~h}$, and the aversion-conditioning procedure was repeated for the peppermint-sucrose solution. Beginning on Day 6, all flavors were presented to animals in Phase 2, utilizing the same matrix as that used in Phase 1; palatability ranks were then compiled. 


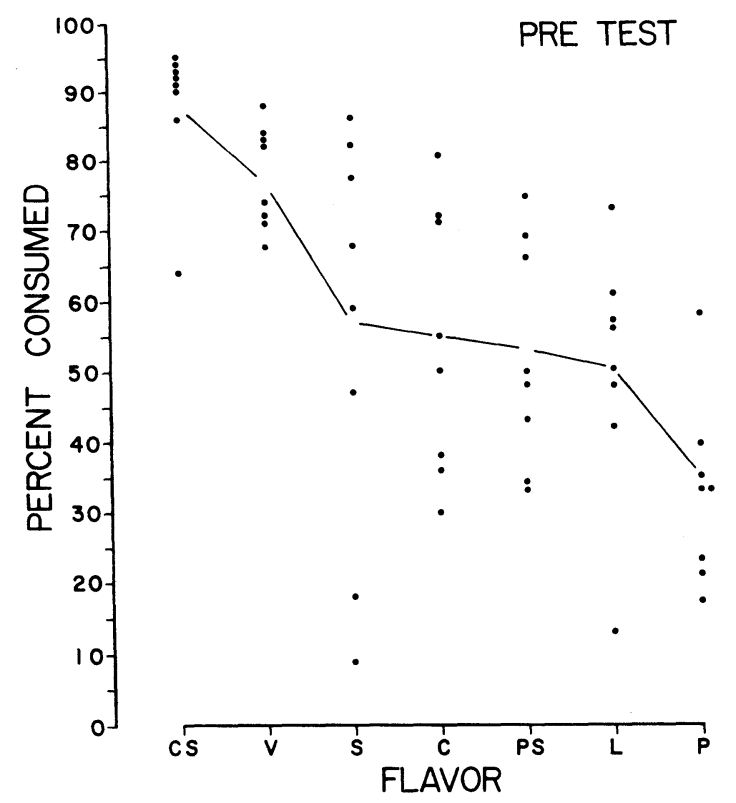

Figure 1. Percent consumption of the seven test solutions, CS-chocolate-sucrose, V-vanilla, S-sucrose, C-chocolate, PS-peppermint-sucrose, L-lemon, $\mathrm{P}$-peppermint. The dots represent individual animals, and the lines connect the mean consumption for each flavor.

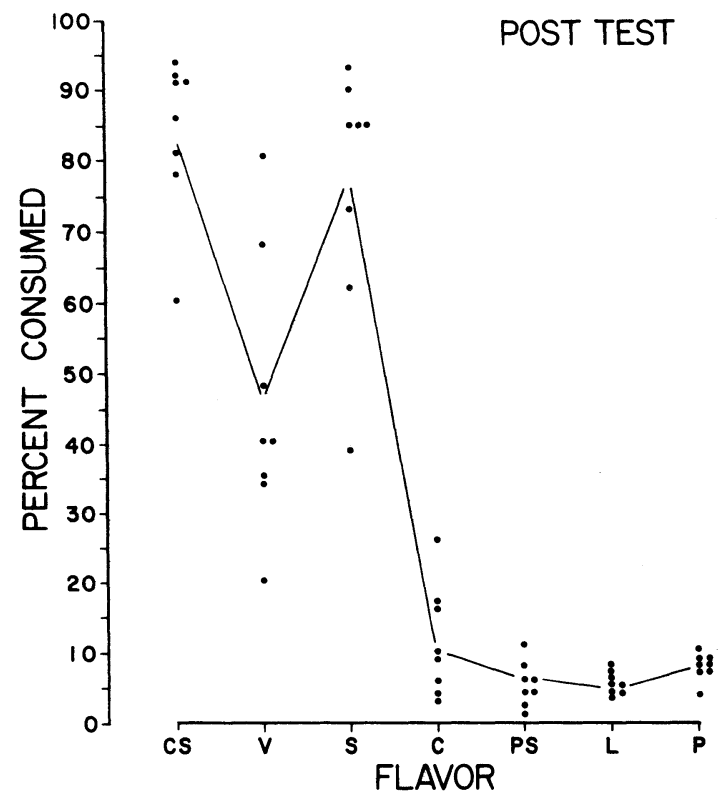

Figure 2. Percent consumption of the seven test flavors following conditioned aversions established for lemon and peppermint-sucrose. The letters are defined in Figure 1.

\section{RESULTS AND DISCUSSION}

The results of the two-bottle choice test are presented in Figure 1. Consumptions above $50 \%$ indicatè that the substance was preferred over tap water. Chocolatesucrose and vanilla are clearly the most palatable flavors. Surprisingly, sucrose did not fare well, but largely because of the wide individual differences (see Figure 1). For the lithium-treated animals (Figure 2), sucrose consumption was much higher, which suggests that the mean value for sucrose obtained during the first palatability testing was abnormally low.

Analysis of variance demonstrated significant differences among the flavors [pretest: $F(6,42)=10.73$, p. $<.001$; posttest: $F(6,42)=71.22, p<.001]$. The Studentized range statistic (Winer, 1962, p. 185f) was used to ascertain specific difference, and these results are summarized in Table 1.

The most important comparisons are between the pre- and posttest consumption. Preference for chocolatesucrose did not change significantly, while preference for vanilla decreased (rank sum test, $p<.001$ ) and sucrose preference increased, although not significantly $(p=.052)$. For all other flavors, a marked reduction in consumption was observed (see Figure 2).

The results suggest that less palatable flavors generalize more readily to taste aversions than do highly palatable flavors. For the less palatable flavors, generalization was so complete that consumption rates were nearly zero and no different from those of the aversion-conditioned flavors themselves. For the most palatable flavor, chocolate-sucrose, posttest palatability did not differ significantly from pretest palatability. For the second most palatable flavor, vanilla, there was a significant decrease from pre- to posttest, but it was

Table 1

Pre and Post Comparison of All Flavors

\begin{tabular}{|c|c|c|c|c|c|c|c|}
\hline \multirow{2}{*}{$\begin{array}{l}\text { Fla- } \\
\text { vors }\end{array}$} & \multirow[b]{2}{*}{ Mean } & \multicolumn{6}{|c|}{$\begin{array}{l}\text { Pretest } \\
\text { Flavors }\end{array}$} \\
\hline & & V & S & C & PS & L & $\mathbf{P}$ \\
\hline $\begin{array}{l}\text { CS } \\
\text { V } \\
\text { S } \\
\text { C } \\
\text { PS } \\
\text { L }\end{array}$ & $\begin{array}{l}88.6 \\
77.6 \\
56.1 \\
54.9 \\
52.4 \\
52.0\end{array}$ & 11 & $\begin{array}{l}32.5^{*} \\
21.5^{*}\end{array}$ & $\begin{array}{c}33.7^{*} \\
22.7^{*} \\
1.2\end{array}$ & $\begin{array}{c}36.2 * \\
25.2^{*} \\
3.7 \\
2.5\end{array}$ & $\begin{array}{c}36.6^{*} \\
25.6^{*} \\
4.1 \\
2.9 \\
.4\end{array}$ & $\begin{array}{l}56.0^{*} \\
45.0^{*} \\
23.5^{*} \\
22.3^{*} \\
19.8^{*} \\
19.4^{*}\end{array}$ \\
\hline \multicolumn{2}{|l|}{ Mean } & 77.6 & 56.1 & 54.9 & 52.4 & 52.0 & 32.6 \\
\hline \multirow{2}{*}{$\begin{array}{l}\text { Fla- } \\
\text { vors }\end{array}$} & \multirow[b]{2}{*}{ Mean } & \multicolumn{6}{|c|}{$\begin{array}{l}\text { Posttest } \\
\text { Flavors }\end{array}$} \\
\hline & & $S$ & $\mathbf{V}$ & $\mathrm{C}$ & PS & L & $\mathbf{P}$ \\
\hline $\begin{array}{l}\text { CS } \\
\text { S } \\
\text { V } \\
\text { C } \\
\text { PS } \\
\text { L }\end{array}$ & $\begin{array}{r}84.6 \\
76.4 \\
46.2 \\
11.8 \\
7.9 \\
7.0\end{array}$ & 8.2 & $\begin{array}{l}38.4^{*} \\
30.2^{*}\end{array}$ & $\begin{array}{l}72.8^{*} \\
64.6^{*} \\
34.4^{*}\end{array}$ & $\begin{array}{c}76.7^{*} \\
68.5^{*} \\
38.3^{*} \\
3.9\end{array}$ & $\begin{array}{c}77.6^{*} \\
69.4^{*} \\
39.2^{*} \\
4.8 \\
.9\end{array}$ & $\begin{array}{c}77.8^{*} \\
69.6^{*} \\
39.4^{*} \\
5.0 \\
1.1 \\
.2\end{array}$ \\
\hline Mean & & 76.4 & 46.2 & 11.8 & 7.9 & 7.0 & 6.8 \\
\hline
\end{tabular}

${ }^{*} p<.01$ 
still supppressed significantly less than the less palatable flavors.

The pattern of preference following lithium conditioning allows one to separate the factors of palatability, salience, and nutrient need. For example, if nutrient need was a dominant factor, it would be expected that flavors with sucrose would behave similarly. However, sucrose alone increased in preference, probably due to a low pretest average. Chocolate-sucrose changed little, if any, while peppermint-sucrose was markedly suppressed. Similarly, if some characteristic of chocolate was responsible for the high palatability of chocolate-sucrose, one would expect a similar result for chocolate. Nevertheless, the conditioned aversion did not generalize to chocolate-sucrose, but did to chocolate. If salience of the flavor was the overriding factor in the generalization of conditioned aversions, one would expect vanilla, a salient flavor, to be more affected than it was.

In conclusion, palatability is a very important factor in the generalization of conditioned taste aversions to novel flavors. Flavors that are relatively less palatable are much more likely to generalize to a conditioned taste aversion than are flavors of higher palatability, and flavors of high palatability show little generalization of a conditioned taste aversion.

\section{REFERENCES}

Brackbill, R. M., Rosenbush, S. H., \& Brookshire, K. H. Acquisition and retention of conditioned taste aversions as a function of taste quality of the CS. Learning and Motivation, 1971, 2, 341-350.

Domsan, M. Poison-induced neophobia in rats. Role of stimulus generalization of conditioned taste aversions. Animal Learning \& Behavior, 1975, 3, 205-212.

ETSCORN, F. Effects of a preferred vs. a nonpreferred CS in the establishment of a taste aversion. Physiological Psychology, 1973, 1, 5-6.

Kalat, J. W., \& Rozin, P. "Salience": A factor which can override temporal contiguity in taste aversion learning. Journal of Comparative and Physiological Psychology, 1970, 7, 192-197.

Kalat, J., \& Rozin, P. Specific hungers and poison avoidance as an adaptive specialization of learning. Psychological Review, 1971, 78, 454-486.

Richter, C. P. Experimentally produced behavior reactions to food poisoning in wild and domesticated rats. Annals of the New York Academy of Science, 1953, 56, 225-239.

Rzoska, J. Bait shyness: A study in rat behavior. British Journal of Animal Behavior, 1953, 1, 128-135.

Vogel, J. R., \& Clody, D. E. Habituation and conditioned food aversions. Psychonomic Science, 1972, 28, 275-276.

WINER, B. J. Statistical principles in experimental design (2nd ed.). New York: McGraw-Hill, 1962.

(Received for publication March 21, 1977.) 